\title{
Strategy Preference Distribution in the Weakest-Link Game: An Analysis Based on Lab Experiments
}

\author{
Yang Huang, Jun Wu, Ya Zhou*, Keqiang Li \\ School of Systems Science, Beijing Normal University, Beijing, China \\ Email: :yzhou@bnu.edu.cn
}

Received 14 March 2016; accepted 13 May 2016; published 16 May 2016

Copyright (C) 2016 by authors and Scientific Research Publishing Inc.

This work is licensed under the Creative Commons Attribution International License (CC BY). http://creativecommons.org/licenses/by/4.0/

(c) (i) Open Access

\begin{abstract}
As many researchers mentioned, in addition to players' different strategy preferences, the expectation towards other players' behavior will jointly affect the coordination level in the weakest-link game. Then how to analyze those factors? To some extent, those factors can be depicted by players' choices in the first round. With the data from several lab experiments, the strategy preferences distribution is discussed in this paper. It is concluded that the overall distribution of the players' initial choices is left skewed, indicating that the players have the motivation to pursue more payoff and the altruistic preference in observed in the beginning of the game. Also, this distribution has no significant difference among all the lab experiments with different treatments, which shows that different coordination levels in the end of different experiment are not due to the initial choice distribution difference. At the same time, no significant distribution difference is found different gender, major in high school and college of players. But then we take a look at the rank of the seven choices, there is significant difference, which shows that different treatment might induce a little difference of the expectation towards other players' behavior, although the overall distribution might be the same.
\end{abstract}

\section{Keywords}

Weakest-Link Game, Equilibrium Selection, Strategy Preference, Expectation

\section{Introduction}

Weakest-link game is one important tool to study group coordination behavior ,which was proposed originally

\footnotetext{
${ }^{*}$ Corresponding author.
}

How to cite this paper: Huang, Y., Wu, J., Zhou, Y. and Li, K.Q. (2016) Strategy Preference Distribution in the Weakest-Link Game: An Analysis Based on Lab Experiments. Open Journal of Social Sciences, 4, 9-14. 
by Van Huyck, Battalio and Bail (VHBB) in 1990 [1], This game has seven multiple Pareto-ranked Nash equilibrium, and the payoff is related to your own choice from 1 to 7 and the smallest choice of the group. Whether a Nash equilibrium be achieved and which one is the biggest concern in the behavioral game analysis with lab experiments, which is called equilibrium selection problem in economic theory. The answer is always coordination failure, however. Strategy uncertainty may be the main reason.

Fehr concluded that selfish preferences might help predict the behavior of the participants, but reciprocal or altruistic preferences also coexisted [2] [3]. Novark found that indirect reciprocity could facilitate the generation of cooperative behavior [4]. In addition, a plenty of literature indicated that expectations and beliefs could affect the coordination level [5]-[8]. Van Huyck had mentioned the choice distribution of the first period was interesting because it had no priori information about others' behavior, which would be the best demonstration of the players' motivation. Cooper had also mentioned that belief, although unpredictable, can reflect the motivation and preference of participants by observing their choices [9]. The same saying was also found in Nagel's guessing game experiment, which said that initially decision makers might rely on pre-judgment without others' information, different "depths of reasoning" may result significant differences in initial selections [10]. So the choice in the first period in the game is of great value to the problem of equilibrium selection. If we want to get a universal conclusion, however, we may need a big dataset from different lab experiments.

Based on 7 experiments about weakest-link game, we did the analysis of strategy preference distribution in this paper, which consists of a total of 420 samples. We focus on whether there are differences in the initial choice distribution, which can depict the initial motivation, expectation and priori belief of other players, as well as differences in strategy preference. As to this topic, Berninghaus and Ehrhart concluded initial selection show no significant difference in different experiments by weak-link game experiments [11]. Crawford also proposed that even if the initial selection modes of participants were different, the final coordination success rate showed slight difference in his dynamical system [12]. Devetag had compared results of the coordination under the three kinds of information feedback mechanism, concluded the participants made no use of signal incentives brought by information feedback initially [13].

\section{Hypothesis}

In the version of the minimum effort game in Van Huyck et al. (1990), players simultaneously select an effort level. Player i's payoff depends on his choice and the minimum effort in the group (Van Huyck et al., 1990). In particular, the payoff for a given subject is: Provided that the payoff function and strategy set are common knowledge, the game has 7 strict Pareto-ranked Nash equilibria, where each subject selects the same effort level with their counterpart. In the payoff-dominant equilibrium, all players select, while in the risk-dominant equilibrium all players select. With the lower equilibrium effort level, the equilibrium payoff decrease gradually.

As mentioned above, the choice distribution of the first period is a reflection to of the initial motivation and strategy preference of players under different treatments. Players will choose to adopt payoff-dominant strategy if he wants to pursue higher payoff, i.e. While a player will choose the risk-dominant strategy if he pursues lower risk, i.e. We can foresee that most the players are risk-neutral and will select an equilibrium among 4, 5 and 6 . At the same time, if a player predicts that all group members will choose a high effort, his own choice will be higher, and on the contrary, if a rational player has priori belief that at least one person would selected 1 , he definitely will not select a choice higher than 1 .

So with the above knowledge, we have made several hypotheses before the analysis.

\section{Hypothesis I: The choice distribution may be a normal distribution with the mean of 4}

This hypothesis is made just because we may argue that players will randomly choose in the first period due to no information about other players' strategies. So the distribution may be a normal curve with the mean of 4 . If so, we may conclude that all the players are indifferent between payoff-dominant and risk-dominant strategies.

Hypothesis II: There is no significant differences in the initial choice distribution among different experiments (treatments) and groups.

If we divide the subjects into different groups, we have no theory or evidence to prove the difference among the groups exist. So we assumes there might be no significant difference. If so, this can give a priori regular pattern about the initial choice in the weakest-link game when we make similar experiment design in future. 


\section{Experiments Summary}

The data used in this paper is from a series of experiments to test the effects of information feedback on coordination behavior. These experiments consists of 7 treatments, which include the Minimum, Full, Distribution, Maximum, Mean, Median and the Number Treatment. In the Minimum Treatment, each subject is merely informed of his payoff and the minimum effort level of the group in the previous period. The Minimum Treatment is the baseline treatment of other 6 treatments. Compared to the Minimum Treatment, each subject in the Full Treatment is informed of more information, including his group members' choices, as well as the maximum and average effort level of the group in the previous period and last ten periods. In the Distribution Treatment, each subject in the group is informed of the distribution of group members' choices in the previous period. Similarly, in the Maximum, Treatment, each subject is informed of the maximum effort level of the group in the previous period. In the Mean Treatment, each subject is informed of the mean effort level of the group in the previous period. In the Median Treatment, each subject is informed of the median effort level of the group in the previous period. In the Number Treatment, each subject is informed of the number of subjects who choose the minimum effort level in the previous period. All treatments stay the same with other experiment conditions. In each treatment, there are 10 groups in each of which 6 subjects play the game simultaneously, and the game repeats 50 times in each group.

When subjects came to the lab, each one was randomly allocated a number which leads him to a seat with a computer. At the beginning of the experiment, the instructions were read aloud and displayed in the computer screen at the same time. All subjects were informed of making his decision alone and keeping silence all the time. These were common knowledge including the group size, fixed group members, the repetition times, the strategies and the payoff table except group members' personal identity. In each period, the subject made his own choice. After all group members' choices were made, the computer system gave them information feedback which showed the payoffs and the choices. After the end of 50th period, subjects filled in a questionnaire and received the payment. The all experiment continued about 45 minutes. Table 1 summarizes the experiment design.

The computerized experiments were programmed in Z-Tree software. All 420 subjects were college students recruited from BBS on campus. Each subject was paid his accumulated payoff of 50 periods in RMB. The exchange rate was 1 yuan per EC (Experiment Currency), and they earned 40.51 yuan in average.

In general, in the 420 subjects, there are 107 (25.5\%) male students and $63.81 \%$ are from majors of science.

\section{Results and Conclusions}

\subsection{Players Have the Motivation to Pursue Higher Payoff, Which Shows That Many Players May Prefer Altruistic Strategy in the Beginning}

Figure 1 depicts the distribution of the choice in the first period. Contrary to our hypothesis, this distribution is left skewed with a SK coefficient of -0.999 ( $p<0.001$ ), which means in the first period, more players prefer high payoffs. As seen from the figure, we know nearly half of the 420 subjects have chosen the strategy of effort 7. This is interesting. Novak ever argued that mankind were altruistic in the beginning instead of selfish through

Table 1. Experiments.

\begin{tabular}{ccc}
\hline Treatment & Time & Location \\
\hline Minimum & $2015.11-12$ & Subjects \\
Full & 2015.12 & Beijing Normal University and Beijing Union University \\
Distribution & 2015.12 & Beijing Normal University \\
Maximum & 2015.12 & Beijing Normal University \\
Mean & 2015.12 & Beijing Normal University \\
Median & 2015.12 & Beijing Normal University \\
Number & Beijing Normal University
\end{tabular}




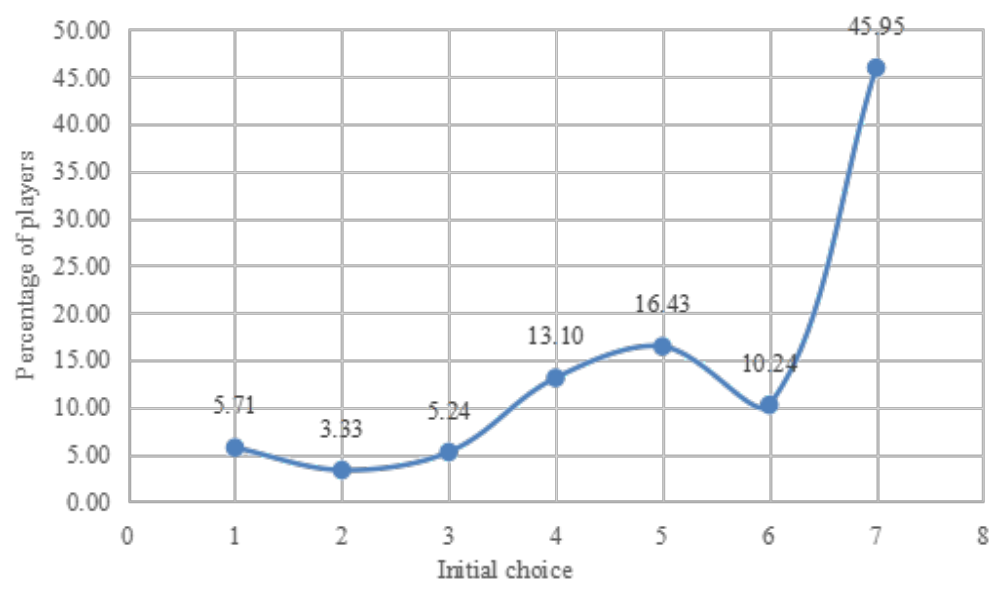

Figure 1. Fitting curve of choices distribution of the first period.

the experience encountered in the public goods game. And here, we have provided another evidence. Further statistics analysis shows that the mean effort level is 5.46 .

Another interesting phenomenon is that there exist three local modes in the distribution, 1, 5 and 7, which shows that if we divide players' choices into three categories, i.e., low, middle and high effort level, players will might choose 1, 5 and 7 as their choice. Here, 1 is one choice of the three, which means if a player wants to exhibit a low effort, he may choose 1 . Effort 1 is an influential strategy in the weakest-link level. Through the statistics, we can see effort 1 is a local mode, although the overall proportion of choosing 1 is only $5.71 \%$.

Also, there shows a gradual increase in the proportion as the effort level increase. We fit the data with both polynomial and exponent means. Hereafter are the results.

$$
\begin{gathered}
y=0.2857 x^{5}-5.1073 x^{4}+33.285 x^{3}-96.101 x^{2}+120.94 x-47.619, \quad R^{2}=0.9991 \\
y=\mathrm{e}^{0.926+0.344 x}, \quad t=3.326, \quad t=0.015, \quad R^{2}=0.724
\end{gathered}
$$

Here, $y$ is the proportion and $x$ means different effort level. Figure 1 shows the fitting curve with polynomial estimation. And the regression result reveals that as the effort level increases, there will be more and more people who will choose that level.

\subsection{No Significant Difference Is Found among Different Experiments and Groups}

In this part, we will test hypothesis II. We will give the results that can illustrate whether the overall distribution is also the same in different groups, i.e., different experiments or different demographic groups. We are concerned about whether those formula still hold among different experiment and groups.

(1) Different experiments

Table 2 shows that mean and median of the choice of the first period in different experiments. And we can see the difference is very small. By performing Kruskal-Wallis tests, we can conclude that there is no significant difference in different experiments, with the test statistic of 8.722 and $p$ value is 0.190 . This result can help test hypothesis II in part and indicates that the distribution can be a priori evidence for future experiment design because it can hold among different experiments. That is to say, in ignorance of the experiment treatment in the weakest-link game, the similar pattern will be found in the forthcoming experiment data.

(2) Different demographic groups

Table 3 summarizes the difference test in the initial choices distribution among different demographic groups, such as different gender, major in high school and college. According to the result, we can see the same conclusion as the former part. Furthermore, by doing correlation test we can see there is no significant correlation between initial selection and player's gender, major in high school, or in college, indicating that the gender, education background composition will not affect the initial selection of players. Then we come to the conclusion that initial motivation exhibit no significant differences in different identity of players. 
Table 2. Descriptive statistics of initial choices in different experiments.

\begin{tabular}{cccccccc}
\hline Treatment & Minimum & Full & Distribution & Maximum & Mean & Median & Number \\
\hline Mean & 5.32 & 5.93 & 5.25 & 5.3 & 5.65 & 5.43 & 5.32 \\
Median & 5 & 7 & 6 & 6.5 & 6 & 6 & 5.5 \\
\hline
\end{tabular}

Table 3. Difference test in the initial choices distribution among different demographic groups.

\begin{tabular}{cccccccc}
\hline & \multicolumn{2}{c}{ Gender } & \multicolumn{2}{c}{ Major in high school } & \multicolumn{3}{c}{ Major in college } \\
\cline { 2 - 8 } & male & female & Science & Arts & natural & social & human \\
\hline mean & 5.37 & 5.49 & 5.51 & 5.36 & 5.57 & 5.32 & 5.43 \\
$\begin{array}{c}\text { sig value in K-W test } \\
\begin{array}{c}\text { sig value in correlation test } \\
\text { with selection }\end{array}\end{array}$ & & 0.651 & & 0.440 & & 0.551 \\
\end{tabular}

\subsection{Some Difference in the Rank of the 3 Local Modes of the Initial Choices Predicts Different Expectation in Different Experiment, Which Shows a Little Strategy Preference Difference}

From part 1, we conclude that the distribution of the initial choices has three local modes. This part we will discuss the preference of the 3 strategies by the 7 different treatments, which can partly illustrate the expectation towards other's player's strategies in the following experiment. Furthermore, because these experiments are designed for the same purpose, we can also judge the players' felling about the usefulness of each information treatment in the following experiment. Table $\mathbf{4}$ summarizes the result, which ranks the 7 treatments according to their proportion chosen within the choices of each local mode. For example, we can see, in all the choices who choose effort 1 , the Maximum treatment is the first one, which means 1/3 of players who choose 1 belong to this group.

With the clear cutting points, we can divide each column into 4 categories, which can be depicted with italics. From the classification, we can get the following conclusions.

1) In Full treatment, the players can get all the other players' choice in the last 10 periods. Without no doubt, in this treatment, players exhibit a high preference towards effort 7 . Also, it attracts player to choose effort 1 , too. This means the distribution may be a dispersed one. We can see the Maximum treatment is almost the same with Full treatment. This might means in such treatments, players will expect the information can help others can coordinate with them.

2) Mean and Median can also attract players to choose higher effort level while not so high as Full treatment and Maximum Treatment.

3) Distribution treatment may cause a fairly average attraction towards all the 3 local modes.

4) Minimum and Number Treatment haven’t attracted higher effort level. Here, the Number treatment is of great value to us for we know that 7 of the 10 experiments have experienced coordination success.

\section{Conclusions}

In summary, with the data from several lab experiments, the strategy preferences distribution is discussed in this paper. It is concluded that the overall distribution of the players' initial choices is left skewed, indicating that the players have the motivation to pursue more payoff and the altruistic preference in observed in the beginning of the game. Also, this distribution has no significant difference among all the lab experiments with different treatments, which shows that different coordination levels in the end of different experiment are not due to the initial choice distribution difference. At the same time, no significant distribution difference is found different gender, major in high school and college of players. But then we take a look at the rank of the seven choices, there is significant difference, which shows that different treatment might induce a little difference of the expectation towards other players' behavior, although the overall distribution might be the same.

However, we must indicate that the results may only be valid for the weakest-link experiments with 6 subjects. 
Table 4. Rank of local mode choices chosen in different treatments.

\begin{tabular}{ccccccc}
\hline \multirow{2}{*}{ rank } & \multicolumn{2}{c}{ No. of 1's } & \multicolumn{2}{c}{ No. of 5's } & \multicolumn{2}{c}{ No. of 7's } \\
\cline { 2 - 7 } & treatment & Column Percent & treatment & Column Percent & treatment & Column Percent \\
\hline 7 & Mean & 4.17 & Full & 7.25 & Number & 11.92 \\
6 & Median & 8.33 & Maximum & 8.70 & Minimum & 12.44 \\
5 & Distribution & 12.5 & Distribution & 11.59 & Distribution & 12.95 \\
4 & Number & 12.5 & Median & 14.49 & Mean & 12.95 \\
3 & Minimum & 12.5 & Mean & 17.39 & Median & 14.51 \\
2 & Full & 16.67 & Number & 18.84 & Maximum & 15.54 \\
1 & Maximum & 33.33 & Minimum & 21.74 & Full & 19.69 \\
\hline
\end{tabular}

The recent literatures have shown many similar experiments with 6 subjects. So we still need more experiments to test if it is valid for experiments with more subjects.

\section{Acknowledgements}

This research was supported by the Fundamental Research Funds for the Central Universities in China.

\section{References}

[1] Van Huyck, J., Battalio, R.C. and Beil, R.O. (1990) Tacit Coordination Games, Strategic Uncertainty and Coordination Failure. American Economic Review, 80, 234-248.

[2] Fehr, E. and Fischbacher, U. (2002) Why Social Preferences Matter-The Impact of Non-Selfish Motives on Competition, Cooperation and Incentives. The Economic Journal, 112, C1-C33. http://dx.doi.org/10.1111/1468-0297.00027

[3] Camerer, C.F. and Fehr, E. (2004) Measuring Social Norms and Preferences Using Experimental Games: A Guide for Social Scientists. Foundations of Human Sociality: Economic Experiments and Ethnographic Evidence from Fifteen Small-Scale Societies. Oxford University Press, Oxford, 55-95. http://dx.doi.org/10.1093/0199262055.003.0003

[4] Nowak, M.A. and Sigmund, K. (2005) Evolution of Indirect Reciprocity. Nature, 437, 1291-1298. http://dx.doi.org/10.1038/nature04131

[5] Stalnaker, R. (1996) Knowledge, Belief and Counterfactual Reasoning in Games. Economics and Philosophy, 12, 133163. http://dx.doi.org/10.1017/S0266267100004132

[6] Crawford, V.P. and Haller, H. (1990). Learning How to Cooperate: Optimal Play in Repeated Coordination Games. Econometrica: Journal of the Econometric Society, 58, 571-595. http://dx.doi.org/10.2307/2938191

[7] Camerer, C. and Hua Ho, T. (1999). Experience-Weighted Attraction Learning in Normal Form Games. Econometrica: Journal of the Econometric Society, 67, 827-874. http://dx.doi.org/10.1111/1468-0262.00054

[8] Danz, D.N., Fehr, D. and Kübler, D. (2012) Information and Beliefs in a Repeated Normal-Form Game. Experimental Economics, 15, 622-640. http://dx.doi.org/10.1007/s10683-012-9317-9

[9] Cooper, R.W., DeJong, D.V., Forsythe, R. and Ross, T.W. (1990) Selection Criteria in Coordination Games: Some experimental Results. The American Economic Review, 80, 218-233.

[10] Nagel, R. (1995) Unraveling in Guessing Games: An Experimental Study. The American Economic Review, 85, 13131326.

[11] Berninghaus, S.K. and Ehrhart, K.M. (1998) Time Horizon and Equilibrium Selection in Tacit Coordination Games: Experimental Results. Journal of Economic Behavior \& Organization, 37, 231-248. http://dx.doi.org/10.1016/S0167-2681(98)00086-9

[12] Crawford, V.P. (1995) Adaptive Dynamics in Coordination Games. Econometrica: Journal of the Econometric Society, 63, 103-143. http://dx.doi.org/10.2307/2951699

[13] Devetag, G. (2002) Coordination and Information in Critical Mass Games: An Experimental Study. Experimental Economics, 6, 53-73. http://dx.doi.org/10.1023/A:1024252725591 